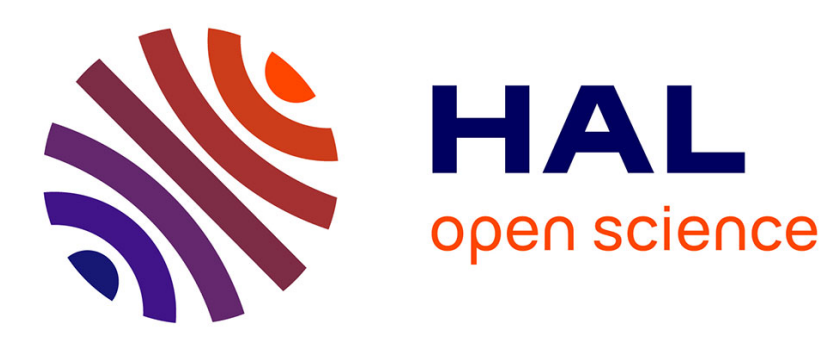

\title{
Obstructive sleep apnoea: from respiratory events to coronary microvascular dysfunction
}

\author{
Sofia Morra, François Roubille
}

\section{To cite this version:}

Sofia Morra, François Roubille. Obstructive sleep apnoea: from respiratory events to coronary microvascular dysfunction. Acta Cardiologica, 2017, pp.319-324. 10.1080/00015385.2017.1384183 . hal01839260

\section{HAL Id: hal-01839260 \\ https://hal.umontpellier.fr/hal-01839260}

Submitted on 18 Dec 2019

HAL is a multi-disciplinary open access archive for the deposit and dissemination of scientific research documents, whether they are published or not. The documents may come from teaching and research institutions in France or abroad, or from public or private research centers.
L'archive ouverte pluridisciplinaire HAL, est destinée au dépôt et à la diffusion de documents scientifiques de niveau recherche, publiés ou non, émanant des établissements d'enseignement et de recherche français ou étrangers, des laboratoires publics ou privés. 


\title{
Obstructive sleep apnoea: from respiratory events to coronary microvascular dysfunction
}

\section{Current opinion about the mechanisms and inter-relationships of ischaemic heart disease and obstructive sleep apnoea}

\author{
Sofia Morra ${ }^{a, b}$ and François Roubille ${ }^{a}$ \\ aDepartment of Cardiology, University Hospital of Montpellier, Montpellier, France; ${ }^{b}$ Department of Cardiac, Thoracic and \\ Cardiovascular Sciences, University of Padua Medical School, Padua, Italy
}

\section{ABSTRACT}

Obstructive sleep apnoea (OSA) is an emerging and independent risk factor for cardiovascular diseases; coronary artery disease (CAD) is higher in OSA patients, even in the absence of other traditional cardiovascular risk factors. There is little evidence to show abnormalities in coronary blood flow (CBF) and disorders in coronary vascular resistance (CVR), occurring during the obstructive respiratory event, suggesting coronary microvascular dysfunction (CMD) as a potential mechanism of ischaemic heart disease (IHD) OSA-as a related consequence.

\section{KEYWORDS}

Obstructive apnoea; intermittent hypoxaemia; coronary artery disease; coronary blood flow; coronary vascular resistance; coronary flow reserve; inflammation; myocardial work; vascular remodelling

\section{Introduction}

OSA is a common sleep-disordered breathing condition frequently found in the general population [1] and more frequently in cardiovascular patients [2-6]. OSA seems to be strongly related to CAD, its prevalence is very high in coronary patients $[7,8]$ and negatively affects short- [9] and long-term [10] prognoses following the acute phase of IHD.

Nowadays, evidence supports OSA as being an independent risk factor for CAD [11], and, in this context, its presence seems to exacerbate nocturnal ischaemic events (both chest pain and ST-segment modifications), that occur mainly in the early morning (5.00-7.00 a.m.) [12]; furthermore, CBF response to the increased myocardial $\mathrm{O}_{2}$ demand seems to be impaired, probably due to an increase in CVR following the obstructive respiratory event [13]. Accordingly, the $\mathrm{AHI}$ has been demonstrated as being an independent, strong predictive factor of impaired CFR [14]. In this paper, we wish to suggest the hypothesis that OSA-related underlying mechanisms of IHD may be associated with coronary microvascular disease, focussing the attention on the role of coronary microvascular function and its disorder found in OSA condition.

\section{Basic concepts}

\section{Inflammation}

The inflammatory state seems to play a key role in the setting of vascular abnormalities, associated with systemic dependent and independent endothelial dysfunction [15].

Where myocardial perfusion is concerned, chronic low-grades of CRP are negatively associated with an impaired CFR, supporting the role of inflammation in the pathophysiology of CMD [16].

Serum levels of CRP [17], TNF $\alpha$, IL-6, IL-8 [18] are elevated in patients with OSA, and evidence supports chronic inflammation as a cardiovascular risk factor [19], resulting in CMD that is, in turn, an early marker of coronary atherosclerosis [20].

\section{Myogenic response of cardiac smooth muscle cells (SMCs) to transmural pressure variations}

Coronary vascular tone is regulated by a number of pathways, as largely explained in a recent review: endothelial mechanisms, metabolic regulation, autonomic nerves circulating hormones and myogenic 
(A) Opposite thoraco-abdominal movements

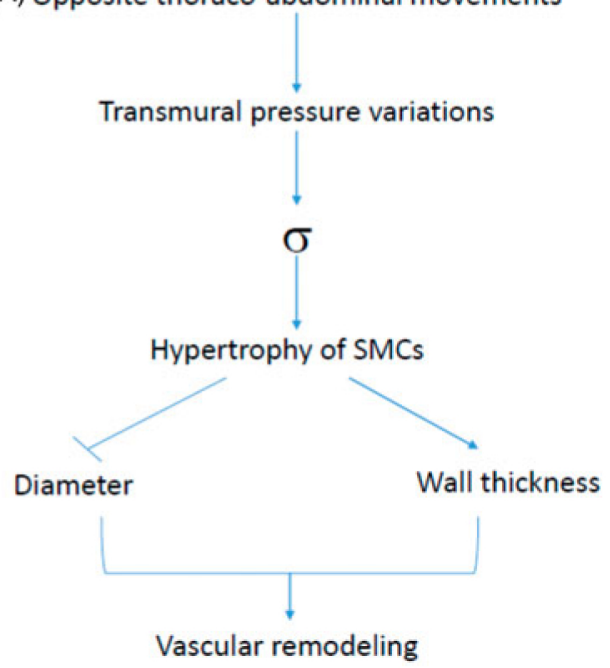

(B)

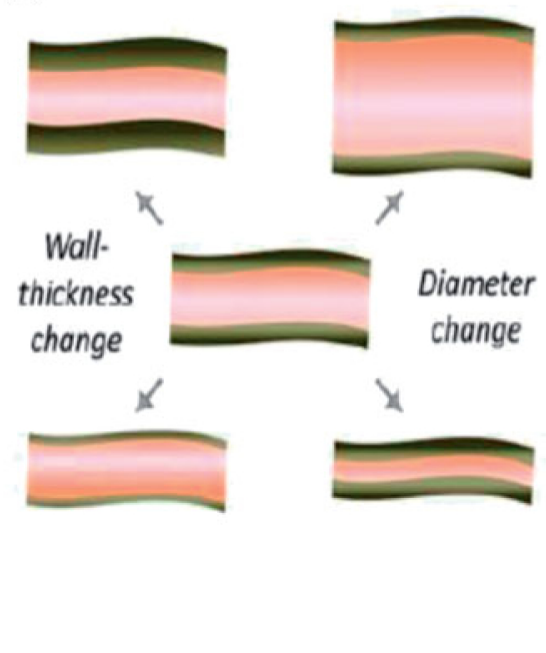

Figure 1. Possible mechanisms of vascular adaptation of coronary arterioles to obstructive respiratory events. (A) Transmural pressure variations are responsible for increase in circumferential wall stress $(\sigma)$ that could lead to hypertrophy of smooth muscle cells (SMCs) and thus, changes in wall thickness and vascular remodelling. (B) Schematic illustration of changing of wall thickness and diameter leading to vascular remodelling. Modified from [21].

response [21]. The latter is the behaviour of blood vessels reacting to pressure elevations with vasoconstriction and to pressure reductions with vasodilatation, in order to establish vascular basal tone, to keep the blood flow constant and to regulate the capillary hydrostatic pressure [22].

The circumferential wall stress on left ventricle due to intermittent but chronic transmural pressure variations as a consequence of obstructive events could be responsible for hypertrophy of smooth muscles cells (SMCs), wall thickness and diameter changes and, at least, for structural remodelling of vessels [21,22] (Figure 1).

The persistent changes in circumferential wall stress drive to long-term vascular adaptation, mainly of the small arteries, and thus, to alterations in flow resistance and perfusion.

Vascular adaptation as a consequence of the inflammatory state, SMCs and endothelial dysfunction could explain alterations in myocardial perfusion observed in OSA patients by affecting coronary microvascular functions.

\section{Coronary microvascular dysfunction}

The term coronary microcirculation identifies two of the three compartments of coronary arterial system, including pre-arterioles $(100-500 \mu \mathrm{m})$ and arterioles $(<100 \mu \mathrm{m})$, the role of which is to maintain an adequate myocardial perfusion in order to assure a correct contractility function [23]. Functional and/or structural abnormalities of this compartment are referred to as $C M D$, in order to describe abnormalities in the regulation of myocardial blood flow and perfusion.

Nonetheless, CMD plays a key role in the pathogenesis of myocardial ischaemic disease, as an additional mechanism to the obstructive disease of epicardial coronary arteries [24,25]. Clinical and pathogenetic classifications of CMD were originally proposed by Camici and Crea in a recent review [25] (Table 1).

Vascular remodelling and endothelial dysfunction are the final common pathway of traditional cardiovascular risk factors (smoking, diabetes, hypertension, dyslipidaemia), in which condition a reduction of CFR can be found [23]. CMD derived from different mechanisms, as illustrated in Table 2.

Structural (vascular remodelling), functional (endothelial dysfunction, dysfunction of smooth muscle cells) and extravascular (extramural compressions) changes are found in OSA condition, and could possibly explain its role as an independent cardiovascular risk factor.

\section{Clinical implications}

\section{Abnormalities of coronary blood flow (CBF) and coronary flow reserve (CFR) occurring during obstructive respiratory events}

During an obstructive apnoeic event, several haemodynamic changes in myocardial flow occur. During an apnoeic event, a transient mismatch between CBF and myocardial work, it is suggested, may occur [13]: in particular, an abnormal delay in CBF rise compared to the rise in RPP and thus, myocardial energy demand, 
Table 1. Classification of coronary microvascular dysfunction.

\begin{tabular}{|c|c|c|}
\hline Type 1: In the absence of myocardial disease and obstructive CAD & $\begin{array}{l}\text { Risk factors } \\
\text { Microvascular angina }\end{array}$ & $\begin{array}{l}\text { Endothelial dysfunction } \\
\text { SMC dysfunction } \\
\text { Vascular remodelling }\end{array}$ \\
\hline Type 2: in myocardial diseases & $\begin{array}{l}\text { Hypertrophic cardiomyopathy } \\
\text { Dilated cardiomyopathy } \\
\text { Anderson-Fabry's disease } \\
\text { Amyloidosis } \\
\text { Myocarditis } \\
\text { Aortic stenosis }\end{array}$ & $\begin{array}{l}\text { Vascular remodelling } \\
\text { SMC dysfunction } \\
\text { Extramural compression } \\
\text { Luminal obstruction }\end{array}$ \\
\hline Type 3: in obstructive CAD & $\begin{array}{l}\text { Stable angina } \\
\text { Acute coronary syndrome }\end{array}$ & $\begin{array}{l}\text { Endothelial dysfunction } \\
\text { SMC dysfunction } \\
\text { Luminal obstruction }\end{array}$ \\
\hline Type 4: iatrogenic & $\begin{array}{l}\mathrm{PCl} \\
\text { Coronary artery grafting }\end{array}$ & $\begin{array}{l}\text { Luminal obstruction } \\
\text { Autonomic dysfunction }\end{array}$ \\
\hline
\end{tabular}

CAD: coronary artery diseases; SMC: smooth muscle cells; PCl: percutaneous coronary intervention. Modified from [25].

Table 2. Pathogenetic mechanisms of coronary microvascular dysfunction.

\begin{tabular}{|c|c|}
\hline Alterations & Causes \\
\hline \multicolumn{2}{|l|}{ Structural } \\
\hline Luminal obstruction & Microembolisation in acute coronary syndrome or after recanalisation \\
\hline Vascular-wall infiltration & Infiltrative heart disease (e.g. Anderson-Fabry's cardiomyopathy) \\
\hline Vascular remodelling & Hypertrophic cardiomyopathy, arterial hypertension, OSA \\
\hline Vascular rarefaction & Aortic stenosis, arterial hypertension \\
\hline Perivascular fibrosis & Aortic stenosis, arterial hypertension \\
\hline \multicolumn{2}{|l|}{ Functional } \\
\hline Endothelial dysfunction & Smoking, hyperlipidaemia, diabetes, OSA \\
\hline Dysfunction of smooth muscle cells & Hypertrophic cardiomyopathy, arterial hypertension, OSA \\
\hline Autonomic dysfunction & Coronary recanalisation \\
\hline \multicolumn{2}{|l|}{ Extravascular } \\
\hline Extramural compression & Aortic stenosis, hypertrophic cardiomyopathy, arterial hypertension, OSA \\
\hline Reduction in diastolic perfusion time & Aortic stenosis \\
\hline
\end{tabular}

Modified from [23]

has been observed (Figure 2). This inadequate response of CBF to myocardial work is more enhanced in case of obstructive rather than central apnoea: in OSA condition, the subsequent rise of CBF slope does not increase at the same rate as RPP one, contrary to CSA events. This difference between the two type of SDB could be explained by the increase in CVR following the obstructive event as seen in panel B of Figure 2, which is not significant in case of central events (Figure 2(D)).

This abnormal response of CVR could be the consequences of transient but repetitive vascular tone changes following the apnoeic event, secondary to the LV wall stress due to the increased intrathoracic pressures.

The main factors regulating $C B F$ are the gradient pressure $(\triangle P)$ originating within the coronary arteries and the left ventricle at the end of the diastolic phase $(\Delta P=$ diastolic pressure in aorta - LV end diastolic pressure) and (VR.

During the apnoeic event, both LV compliance and LV end-diastolic volume decrease as consequence of increased venous return due to the enhanced negative intrathoracic pressure; this could lead to an increase in the LV end-diastolic pressure, in a reduction in the coronary $\Delta P$ and thus $C B F$, partially explaining its inappropriateness to the increased myocardial work occurring throughout the obstructive apnoea. If we carefully focus our attention on CSA, the generation of negative intrathoracic pressure is less exaggerated than that observed in OSA [26], may be resulting in a more adequate response of CBF to myocardial energy demand (Figure 2(C)).

Nevertheless, this impairment of CBF could also be the consequence of an increase in CVR, as explained above (Figure 2(B)). The abnormal rise of CVR is responsible for a reduction in $\mathrm{CBF}$ at maximal vasodilation, resulting in a dysfunction of coronary flow reserve (CFR $=\mathrm{CBF}$ at maximal vasodilation/CBF at rest). Accordingly, Wang et al. showed an inverse relationship between CFR and the severity of OSA in patients affected with cardiac syndrome $X$ (CSX) and an increased chance of having low CFR as the AHI rises [14].

In the same study, $\mathrm{AHI}$ emerges as a strong, independent predictor of impaired CFR and, in turn, correlates to coronary microvascular dysfunction. 
(A)

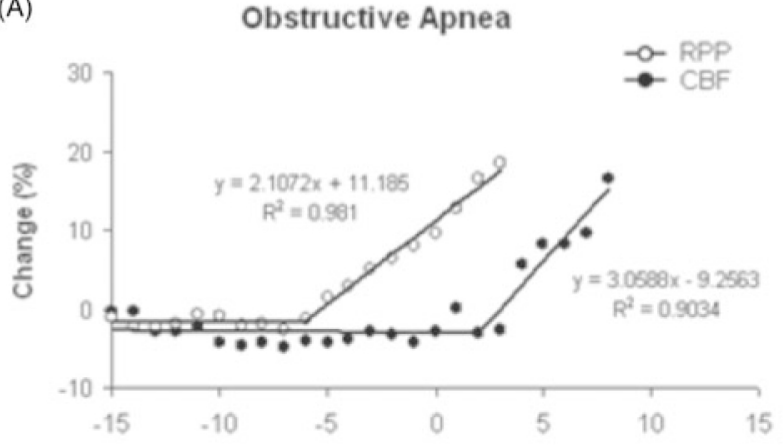

(C)

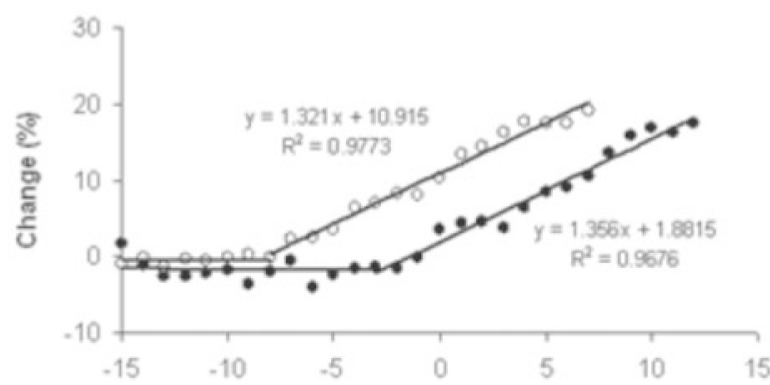

(B)

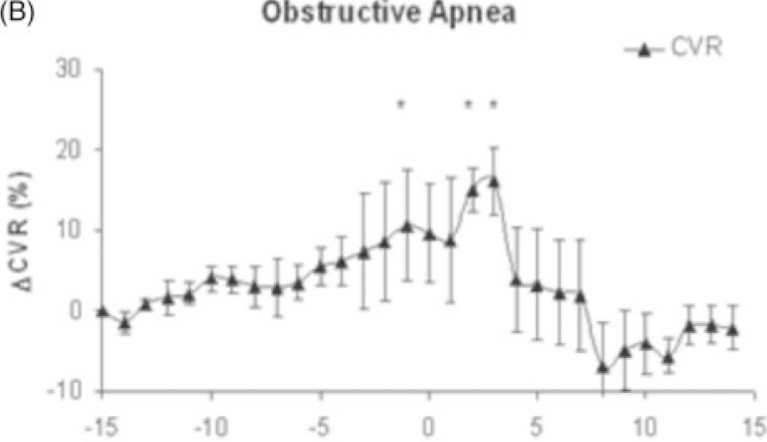

(D)

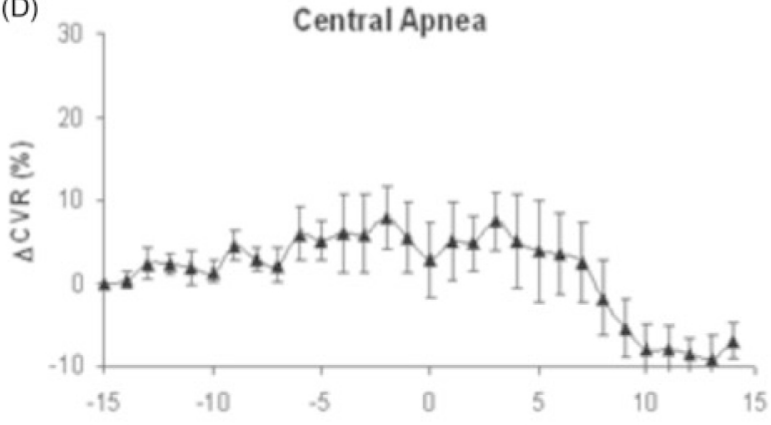

Figure 2. (A) Coronary blood flow (CBF) rise is delayed compared with in myocardial work energy demand, expressed by ratepressure product (RPP). (B) Coronary vascular resistance (CVR) increases at the end of obstructive apnoea and this could explain the impairment of CBF response to myocardial work. On the other hand, during the central apnoeic event, the belated rise of CBF is less enhanced (C) as well as the increase in CVR (D). Modified from [13]. CBF: coronary blood flow; CVR: coronary vascular resistance; RPP: rate-pressure product.

A/ OSA and CFR

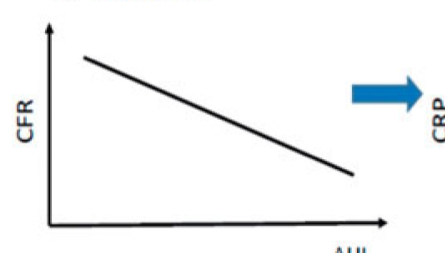

AHI
B/ OSA and CRP levels

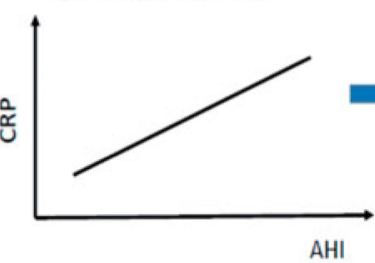

C/ CFR and chronic inflammatory disease

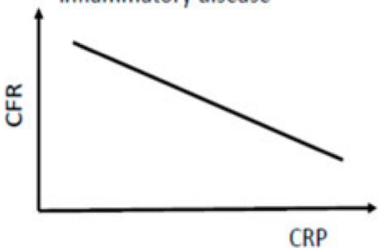

Figure 3. Obstructive sleep apnoea (OSA) could be considered a chronic inflammatory disease. High levels of C-reactive protein (CRP), as well as high apnoea-hypopnoea index (AHI) values, are inversely associated to low coronary flow reserve (CFR) (panels $A$ and $\mathrm{C}$ ). Nonetheless, greater AHI values are associated with high CRP levels (panel B). Panel A: modified from [14]; Panel B: modified from [17]; Panel C: modified from [16]. AHI: apnoea-hypopnoea index; CFR: coronary flow reserve; CRP: C-reactive protein; OSA: obstructive sleep apnoea.

Possible mechanisms linking OSA to CMD, expressed as an impaired CFR, could be the inflammatory state and the mechanical stress on LV wall, secondary to exaggerated negative intrathoracic pressure with both phenomena paving the way to vascular remodelling.

High levels of CRP are linked to lower CFR as well [16]: in OSA condition, there are high plasma levels of CRP [17] so that inflammation may be responsible for the impairment of CFR observed in OSA state. This could also apply to other chronic inflammatory diseases, such as rheumatoid arthritis (RA) and systemic lupus erythematosus (SLE) [20] (Figure 3).
To summarise, CMD can reasonably be proposed as an underlying mechanism linking OSA to ischaemic heart disease. This disorder in coronary resistance vessels could be the consequence of vascular remodelling of pre-arterioles and arterioles of coronary arterial system, resulting from the interaction of different mechanisms, as set out in Figure 4.

\section{Conclusions}

Increasingly, OSA is considered as an emerging risk factor for coronary artery diseases; the underlying mechanism remains unclear. Even though the frequent 


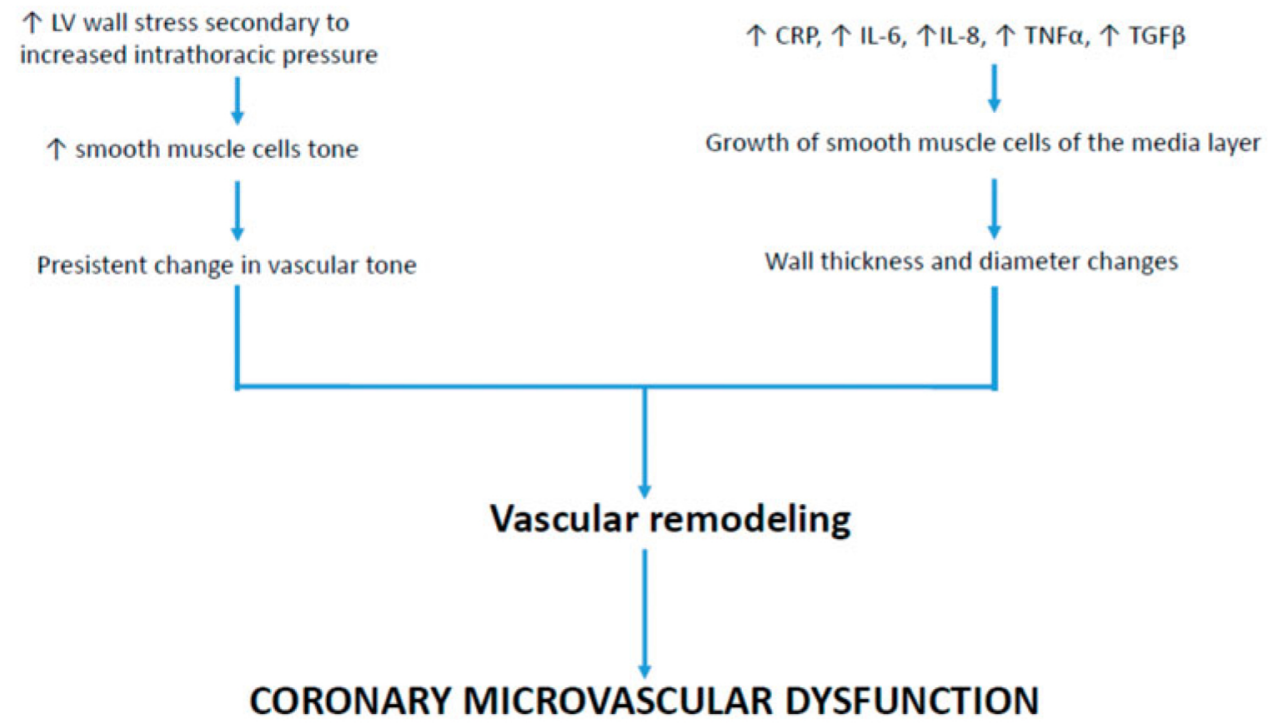

Figure 4. Possible multiple mechanisms explaining vascular remodelling of small artery vessels in myocardial muscle, leading to microvascular dysfunction. The increased LV wall stress due to intrathoracic negative pressure is a strong stimulus to vascular tone changing, mainly caused by the myogenic response; the persistent increased vascular tone drives long-term vascular adaptation by structural remodelling. The increased release of cytokines due to the abnormal inflammatory state, can induce local production of growth factors, such as TGF $\beta$, that stimulates smooth muscle cells of the media layer to proliferation; all these abnormalities pave the way to vascular remodelling and thus, to coronary microvascular dysfunction.

co-existence of traditional cardiovascular risk factors, which often muddle the direct cause-effect relationships, interestingly, there is little evidence to show the emergence of ischaemic heart disease, from cardiac syndrome $\mathrm{X}$ to acute coronary syndrome, in apnoeaic, but otherwise healthy people. Microvascular coronary dysfunction may be suggested as a potential mechanism of OSA-related IHD; making this syndrome an independent cardiovascular risk factor.

\section{Disclosure statement}

No potential conflict of interest was reported by the authors.

\section{References}

[1] Young T, Palta M, Dempsey J, et al. The occurrence of sleep-disordered breathing among middle-aged adults. N Engl J Med. 1993;328:1230-1235.

[2] Bradley TD, Floras JS. Obstructive sleep apnoea and its cardiovascular consequences. Lancet (London, England). 2009;373:82-93.

[3] Guilleminault C, Connolly SJ, Winkle RA. Cardiac arrhythmia and conduction disturbances during sleep in 400 patients with sleep apnea syndrome. Am J Cardiol. 1983;52:490-494.

[4] Oldenburg O, Lamp B, Faber L, et al. Sleep-disordered breathing in patients with symptomatic heart failure: a contemporary study of prevalence in and characteristics of 700 patients. Eur J Heart Fail. 2007;9:251-257.

[5] Parish JM, Somers VK. Obstructive sleep apnea and cardiovascular disease. Mayo Clin Proc. 2004;79: 1036-1046.
[6] Paulino A, Damy T, Margarit L, et al. Prevalence of sleep-disordered breathing in a 316-patient French cohort of stable congestive heart failure. Arch Cardiovasc Dis. 2009;102:169-175.

[7] Konecny $T$, Kuniyoshi FH, Orban M, et al. Under-diagnosis of sleep apnea in patients after acute myocardial infarction. J Am Coll Cardiol. 2010;56:742-743.

[8] Lee $\mathrm{CH}$, Khoo SM, Tai BC, et al. Obstructive sleep apnea in patients admitted for acute myocardial infarction. Prevalence, predictors, and effect on microvascular perfusion. Chest. 2009;135:1488-1495.

[9] Barbe F, Sanchez-de-la-Torre A, Abad J, et al. Effect of obstructive sleep apnoea on severity and short-term prognosis of acute coronary syndrome. Eur Respir J. 2015;45:419-427.

[10] Gottlieb DJ, Yenokyan G, Newman AB, et al. Prospective study of obstructive sleep apnea and incident coronary heart disease and heart failure: the sleep heart health study. Circulation. 2010;122:352-360.

[11] [Recommendations for clinical practice. Obstructive sleep apnea hypopnea syndrome in adults]. Rev Maladies Respirat. 2010;27:806-833.

[12] Peled N, Abinader EG, Pillar G, et al. Nocturnal ischemic events in patients with obstructive sleep apnea syndrome and ischemic heart disease: effects of continuous positive air pressure treatment. J Am Coll Cardiol. 1999;34:1744-1749.

[13] Hamilton GS, Meredith IT, Walker AM, et al. Obstructive sleep apnea leads to transient uncoupling of coronary blood flow and myocardial work in humans. Sleep. 2009;32:263-270.

[14] Wang N, Li SB, Zhao LS, et al. Relationship between obstructive sleep apnea and coronary microcirculatory function among patients with cardiac syndrome $X$. Coronary Artery Dis. 2014;25:35-39. 
[15] Tondi P, Santoliquido A, Di Giorgio A, et al. Endothelial dysfunction as assessed by flow-mediated dilation in patients with cardiac syndrome $\mathrm{X}$ : role of inflammation. Eur Rev Med Pharmacol Sci. 2011; 15:1074-1077.

[16] Recio-Mayoral A, Rimoldi OE, Camici PG, et al. Inflammation and microvascular dysfunction in cardiac syndrome $X$ patients without conventional risk factors for coronary artery disease. JACC Cardiovasc Imaging. 2013;6:660-667.

[17] Shamsuzzaman AS, Winnicki $M$, Lanfranchi $P$, et al. Elevated C-reactive protein in patients with obstructive sleep apnea. Circulation. 2002;105:2462-2464.

[18] Ryan S, Taylor CT, McNicholas WT. Predictors of elevated nuclear factor-kappaB-dependent genes in obstructive sleep apnea syndrome. Am J Respir Crit Care Med. 2006;174:824-830.

[19] Willerson JT, Ridker PM. Inflammation as a cardiovascular risk factor. Circulation. 2004;109:II2-I10.

[20] Recio-Mayoral A, Mason JC, Kaski JC, et al. Chronic inflammation and coronary microvascular dysfunction in patients without risk factors for coronary artery disease. Eur Heart J. 2009;30:1837-1843.

[21] Pries AR, Badimon L, Bugiardini R, et al. Coronary vascular regulation, remodelling, and collateralization: mechanisms and clinical implications on behalf of the working group on coronary pathophysiology and microcirculation. Eur Heart J. 2015;36:3134-3146.

[22] Davis MJ, Hill MA. Signaling mechanisms underlying the vascular myogenic response. Physiol Rev. 1999; 79:387-423.

[23] Camici PG, Crea F. Coronary microvascular dysfunction. N Engl J Med. 2007;356:830-840.

[24] Camici PG, d'Amati G, Rimoldi O. Coronary microvascular dysfunction: mechanisms and functional assessment. Nat Rev Cardiol. 2015;12:48-62.

[25] Crea F, Camici PG, Bairey Merz CN. Coronary microvascular dysfunction: an update. Eur Heart J. 2014;35:1101-1111.

[26] Bradley TD, Floras JS. Sleep apnea and heart failure: Part II: central sleep apnea. Circulation. 2003;107: $1822-1826$. 